\title{
Didáctica de la literatura: ¿cómo se contagia la literatura?*
}

Fecha de recepción: 12 de agosto de 2015

Fecha de aprobación: 02 de febrero de 2016

\section{Resumen}

El artículo tiene como objetivo proponer una estrategia de contagio de la literatura para la intervención práctica en la educación literaria de los estudiantes. Se propone el modelado estético como una estrategia pertinente para transmitir la pasión por la literatura. $\mathrm{La}$ propuesta se sustenta en la teoría del contagio literario, la pedagogía dialogante y la estética general. La formulación de la estrategia se inspira, por un lado, en el modelado cognitivo de Bandura y, por el otro, en las experiencias pedagógicas del escritor Vladimir Nabokov, quien ejerció la educación literaria con mucho éxito. A partir del análisis de las clases y testimonios de Nabokov, se elabora el modelado estético con sus respectivos procedimientos didácticos. Esta estrategia puede ser una alternativa didáctica para educar la sensibilidad literaria de los estudiantes.

Palabras clave: modelado estético verbal, contagio literario, didáctica de la literatura.

Citar: Altamirano Flores, F. (enero-junio de 2016). Didáctica de la literatura: ¿cómo se contagia la literatura? La Palabra, (28), 155-171. doi: http://dx.doi. org/10.19053/01218530.4813

\section{Federico Altamirano Flores}

Universidad Nacional de San Cristóbal de Huamanga. Magíster en Filología Hispánica por el Instituto de la Lengua Española del Consejo Superior de Investigaciones Científicas de Madrid, y Magíster en Formación del Profesores de Español como Lengua Extranjera por Universidad de León (España). faltamiranoflores@yahoo.com

* Artículo de revisión derivado de la investigación del mismo título realizada en 2014 con el financiamiento de la Unidad de Investigación e Innovación de la Universidad Nacional de San Cristóbal de Huamanga. 


\title{
la palabra
}

\section{Didactics of Literature: Literary Teaching as a Form of Contagion}

\begin{abstract}
The objective of this article is to propose a strategy of contagion of literature as a means for practical intervention in the literary education of students. We propose aesthetic modeling as a pertinent strategy to transmit the passion for literature. This proposal is based in the theory of literary contagion, dialogical pedagogy and general aesthetics. The formulation of this strategy is inspired, on the one hand by Bandura's concept of cognitive modeling, and on the other, by the pedagogical experiences of the writer Vladimir Nabokov and his successful experience in literary education. Through an analysis of the classes and testimonies of Nabokov, we offer the concept of "aesthetic modeling", with its corresponding didactic procedures, as an alternative didactic strategy for educating the literary sensibility of students.
\end{abstract}

Key words: Verbal aesthetic model, literary contagion, didactics of literature.

\section{Didactique de la littérature : comment transmettre la littérature?}

\section{Résumé}

L'article propose une stratégie de transmission de la littérature pour faire une intervention pratique dans l'éducation littéraire des étudiants. On propose un modèle esthétique comme stratégie pertinente pour transmettre la passion pour la littérature. La proposition est soutenue par la théorie de la transmission littéraire, la pédagogie du dialogue et l'esthétique générale. La formulation de la stratégie s'inspire, d'un côté, par la vision cognitive de Bandura et, d'un autre, par les expériences pédagogiques de l'écrivain Vladimir Nabokov qui s'est occupé de l'éducation littéraire avec beaucoup de succès. A partir de l'analyse des classes et des témoignages de Nabokov, on construit le modèle esthétique avec leurs procédures didactiques respectives. Cette stratégie peut-être une alternative didactique pour cultiver une sensibilité littéraire des étudiants.

Mots clés : modèle esthétique verbal, transmission littéraire, didactique de la littérature. 


\section{He tratado de enseñaros a leer libros por amor a su forma, a sus visiones, su arte}

(Nabokov, 2010)

\section{Introducción}

"Me parece una barbaridad pedagógica anteponer la enseñanza de la literatura a la formación y afinamiento de la sensibilidad artística, o de la educación estética", decía Luis Landero (1994, p. 28), un escritor con vasta experiencia pedagógica en la educación literaria. ¿Cuál es la observación pedagógica de Landero? Landero cuestiona la práctica de la enseñanza de la literatura antes que la educación literaria. Esto se debe a que la enseñanza está asociada a la transmisión de informaciones sobre la literatura: contextos literarios, autores y obras, términos literarios, argumentos, datos referenciales y analíticos sobre los textos literarios. Las informaciones literarias producidas por críticos, teóricos o profesores de literatura pueden convertirse por sí mismos en conocimiento $\mathrm{y}$ no se traducen en experiencias literarias auténticas y personales. Los estudiantes pueden asimilar mucha información literaria sin haber tenido ningún contacto directo con la obra; por lo mismo, pueden recordarla sin mucho esfuerzo a la hora del examen. Sin embargo, Landero no acepta que se sacrifique la educación estética verbal de los estudiantes en el aula, por la aplicación de una pedagogía literaria que privilegie operaciones puramente cognitivas. Está convencido de que la literatura primero se contagia y luego se enseña. Alterar esta secuencia pedagógica le parece absurdo y contraproducente. Por eso puntualiza: "no se puede enseñar la literatura en sentido estricto, salvo a quienes previamente estén poseídos ya por el demonio de la literatura" (Landero, 1994, p. 28). Él, como Daniel Pennac, Jorge Luis Borges, Ricardo Piglia, Vladimir Nabokov, Julio Cortázar, etc., apuesta por el contagio del entusiasmo literario antes que por la enseñanza de la literatura. Exige que la primera tarea de la didáctica de la literatura ha de ser la formación de la sensibilidad literaria de los estudiantes a través de la lectura directa de los textos.

"No hay forma más segura de adquirir el gusto por la lectura que a través del contagio del entusiasmo lector", afirma Argüelles (2009, p. 219). Por esta razón, aunque Lázaro Carreter (1991) dude de la existencia de un "método que haga lectores" (p. 32), sugerimos una estrategia didáctica del contagio literario: el modelado estético. Esta estrategia se propone a partir del análisis de las clases de Vladimir Nabokov, quien, con mucha maestría, contagió su pasión por la literatura a sus estudiantes cuando se desempeñó como profesor de la misma. El modelado estético se sustenta en la teoría del contagio literario, la pedagogía dialogante y la estética general. Estas disciplinas, sobre todo las dos últimas, aportan ideas para configurar una propuesta de educación estética verbal.

La noción de modelado se toma de la teoría cognitiva social de Bandura (1984). Dentro de esta teoría, el modelado es una forma de aprendizaje de conductas sociales nuevas. Pero también puede ser una estrategia didáctica en cuanto se utilice en el entrenamiento de las habilidades sociales como la educación literaria o la adquisición de la competencia literaria. Entonces, ya concebimos el modelado estético como una estrategia didáctica con su correspondiente procedimiento didáctico, que consta de cuatro fases enfocadas en la provocación literaria por parte del profesor. La estrategia del modelado estético, nacida de la práctica pedagógica de los escritores, se centra en la formación de la sensibilidad literaria de los estudiantes para hacerlos lectores apasionados.

Fundamentos de la estrategia del contagio literario

\section{La teoría del contagio literario}

Altamirano (2012) plantea que la didáctica de la literatura tiene 
dos funciones fundamentales:

(a) el contagio de la literatura y

(b) la enseñanza de la literatura.

Estas funciones deben ejecutarse en ese orden lógico porque la segunda exige la concreción de la primera cuando se pretende desarrollar la educación literaria. Cuando se altera ese orden, "[1]a sensibilidad literaria es lo primero que se mata en la escuela" (Argüelles, 2009, p. 134) y, por lo mismo, la educación literaria desaparece para dar paso a una materia de estudio de corte cognitivista.

La noción del contagio literario surge a partir de la reflexión sobre las creencias y prácticas pedagógicas de algunos escritores importantes (Daniel Pennac, Jorge Luis Borges, Luis Landero, Vladimir Nabokov, Julio Cortázar) que ejercieron la educación literaria; en cambio, el concepto de enseñanza de la literatura proviene de la didáctica de la literatura basada, fundamentalmente, en las teorías literarias. El concepto del contagio literario es un término compartido por los citados escritores. Ellos, en el ejercicio de la educación literaria, tienen como objetivo principal transmitir la pasión por la literatura con el fin de que los estudiantes gocen con el arte verbal así como lo han hecho ellos. En cambio, los profesores de literatura, siguien-do los manuales de didáctica de la literatura basada en las teorías literarias (Cassany, 1998; Lomas, 1999; González, 2001; Mendoza, 2003; Garrido,
2004; Prado, 2004; Abril, 2004; López y Fernández, 2005; Vivante, 2006; Leibrandt, 2008; Martín, 2009), profesan la enseñanza de la literatura; es decir, enseñan el conocimiento sobre la literatura. Por consiguiente, propician en sus estudiantes el análisis de textos y la acumulación de la información sobre los contextos literarios. Enseñan la lectura "eferente", en la que la atención del lector "está centrada en averiguar qué debe hacer al terminar la lectura" (Rosenblatt, 1996). Concentran su preocupación didáctica en entrenar a los estudiantes en el análisis literario. Pero "[1]a finalidad del análisis de las obras en la escuela no debería seguir siendo ilustrar los conceptos que acaba de introducir tal o cual lingüística, tal o cual teórico de la literatura $[\ldots]$ Su labor debería ser permitirnos acceder a su sentido" (Todorov, 2009, pp. 98-99).

El contagio de la literatura se define como la transmisión de un sentimiento estético verbal del profesor hacia los alumnos a través del acto de la comunicación literaria modélica, para despertar en ellos el entusiasmo que conduzca al disfrute de la literatura de manera directa y personal (Altamirano, 2012, p. 26). El sentimiento estético literario no se puede enseñar, solamente se puede transmitir porque la experiencia literaria no puede "reproducirse mediante operaciones puramente conscientes" (Vigotski, 1972, p.
314). El sentimiento estético de la literatura escapa a la lógica de la explicación y de la enseñanza porque las sensaciones que brotan del cuerpo y de la mente de cada lector no son producto de las interpretaciones mediadas por el razonamiento. Por ello, con justa razón, Barthes (1989) sostenía que el "placer del texto es ese momento en que mi cuerpo comienza a seguir sus propias ideas -pues mi cuerpo no tiene las mismas ideas que yo-" (p. 29). Para Barthes, el placer del texto es la satisfacción emocional como producto del estímulo textual; es "decible" en el proceso de la comunicación literaria, y es extensivo al goce. En cambio, "el goce es indecible" (Barthes, 1989, p. 35) porque no se puede traducir en discurso, pues el que "goza desvanece toda letra". El placer estético no es simplemente el deleite sensual, sino es la capacidad interior de representar imaginariamente un universo simbólico; es un goce que, habiendo pasado por los sentidos, configura el espíritu o la consciencia humana. E1 placer estético es una forma de experimentarse uno mismo en esa capacidad de ser otro a partir de la recepción de la experiencia ajena. Por ello, los sentimientos producidos por la literatura se experimentan en lo íntimo y constituyen la respuesta afectiva que mueve al lector internamente. No se pueden enseñar porque el acto de la sensación literaria es personal e intransferible. Esto no significa que el profesor de 
literatura no pueda contribuir a bien se contagia" (p. 28). su manifestación y formación.

El contagio literario tiene como objetivo central despertar, desarrollar y cultivar el goce estético $^{1}$ en el proceso de la educación literaria porque la "experiencia sensorial" (Jauss, 1992, p. 37) constituye el primer nivel de las experiencias en el hombre. De tal modo, las experiencias sensoriales, como el asombro, la admiración, la risa, la compasión, la tristeza, el llanto, la conmoción, etc., son reacciones naturales del cuerpo ante las representaciones estéticas de la vida humana en el proceso de la reconstrucción de la literatura. En este sentido, con mucha razón, Jauss (1992) sostiene que, en el arte, el placer consiste en "la rendición sensual directa del yo ante un objeto" (p. 30). Esa "rendición sensual" produce la satisfacción estética en el lector o en el interlocutor y es fundamental para reconstruir el objeto estético ${ }^{2}$. Sin la participación activa de los sentidos afectivos no se puede percibir la literatura como arte. Entonces, el propósito final de la teoría del contagio literario es la educación de la sensibilidad literaria, porque, como decía Landero (1994), "la sensibilidad no se enseña: más
Considerando el poder comunicativo de la literatura, "no debemos enseñar sobre la literatura, debemos en cambio hacer vivir la literatura a nuestros estudiantes" (Rosenblatt, 2002, p. 22). Vivir la literatura es la misma experiencia literaria o la "experiencia estética" como señala Jauss (1992); no tiene un propósito cognitivo ni busca la verbalización abstracta de corte intelectualista, sino más bien tiene un propósito estético porque exige que el receptor preste más atención a los aspectos afectivos en la interacción con el texto literario. "Lo que ahora importa es recuperar nuestros sentidos. Debemos aprender a ver más, a oír más, a sentir más" (Sontag, 1984, p. 9). La comunicación literaria centrada en el placer estético despliega los sentidos afectivos para construir la representación artística del texto. A partir de la combinación de sensaciones, sentimientos, imágenes e ideas, se estructura la experiencia literaria.

\section{La pedagogía dialogante}

La pedagogía dialogante de Luis Not $(1983,1992)$ se sustenta en la teoría de la comunicación humana porque distingue la inscripción de las tres personas (yo, tú y él) en el discurso pedagógico. La concepción comunicativa de la enseñanza de Not toma en cuenta quién habla y a quién. A partir de esta distinción, después de analizar los modelos pedagógicos tradicionales, descubre que la educación tradicional se desarrolla en tercera y primera persona. La educación en tercera persona ("heteroestructurante") concibe al estudiante como objeto pasivo y privilegia al profesor como protagonista de la actividad educativa. En cambio, la educación en primera persona ("autoestructurante") toma al estudiante como sujeto activo y centro del proceso educativo; ve a los estudiantes como los verdaderos constructores de sus propias experiencias y aprendizajes. Estos modelos pedagógicos tienen limitaciones porque privilegian solamente a uno de los sujetos pedagógicos: o bien a la primera persona, o bien a la tercera persona.

Para superar las limitaciones de estos enfoques pedagógicos, Not propone la educación en segunda persona ("interestructuración"), fundada en la dialéctica hegeliana y en el interaccionismo social de

\footnotetext{
En cambio, la didáctica de la literatura centrada en la enseñanza pone énfasis en la dimensión cognitiva del lector; por ello, en el aula, gestiona actividades de aprendizaje sobre el contenido del texto literario, dejando de lado la forma textual. Para esta didáctica, "el comentario de textos se convierte en una práctica habitual en las aulas de la educación secundaria con la idea de que sólo mediante el análisis científico de los textos literarios es posible contribuir a la adquisición de habilidades interpretativas y de competencias lectoras por parte del alumnado" (Lomas, 2002, p. 44).

2 Jauss (1992) plantea dos modalidades de experiencia estética: la sensación y la construcción de sentido. Mediante estas modalidades, el lector se vincula con la literatura.
} 
Vigotski. Este enfoque constituye la síntesis dialéctica de ambos enfoques porque reconoce la existencia de un sujeto que enseña y un sujeto que aprende, lo que significa que rechaza el alumno objeto del primer enfoque y al maestro ausente del segundo. En la educación en segunda persona, el tú (alumno o profesor) es el otro con quien el yo (profesor o alumno) establece la interacción dialógica. Así se restituye el rol esencial del profesor y se coloca al alumno en el centro de las iniciativas y actividades de aprendizaje. De tal modo, la educación en la segunda persona hace que el alumno construya su saber con la participación mediadora del profesor; así la acción de éste sobre el alumno se transforma en acción hacia el alumno (Not, 1992).

Por su parte, De Zubiría (2011), a partir del enfoque interestructurante de Not (educación en segunda persona), desarrolla el modelo dialogante. Este modelo reconoce que

el conocimiento se construye por fuera de la escuela, pero que es reconstruido de manera activa e interestructurada a partir del diálogo pedagógico entre el estudiante, el saber y el docente, y para que ello ocurra es condición indispensable contar con la mediación adecuada del maestro, que favorezca de manera in- tencionada, significativa y trascendente el desarrollo integral del estudiante. [...] Así postulamos un modelo que concluya que la finalidad de la educación no puede estar centrada en el aprendizaje, como hace siglos ha creído la escuela, sino en el desarrollo (pp. 17-18).

El modelo dialogante toma en cuenta el papel activo del estudiante en el proceso educativo y el rol esencial de los profesores como mediadores culturales, yendo más allá de la noción de aprendizaje como finalidad educativa. Su finalidad principal no es producir solamente aprendizaje, sino más bien apuesta por el desarrollo personológico o integral del estudiante; es decir, se propone desarrollar las diversas dimensiones humanas del estudiante: la dimensión cognitiva, la dimension afectiva y la dimensión práctica, puesto que un sujeto piensa, siente y actúa. También reconoce que los procesos cognitivos, afectivos y praxiológicos están determinados por los contextos históricos, sociales y culturales en los que viven los sujetos de la educación. Comprende que la educación es una práctica social situada en un contexto concreto.

\section{La estrategia del contagio} literario

A la luz de los fundamentos planteados en el apartado ante- rior, proponemos una estrategia didáctica que pueda servir para contagiar la literatura a los estudiantes que aún no están infectados con el virus de la literatura. La mejor forma de adquirir el gusto por la lectura literaria es a través del contagio de la pasión lectora. En este sentido, estamos de acuerdo con Argüelles (2009) cuando sostiene que un

adulto que disfruta el placer de leer contagia ese placer, incluso sin proponérselo deliberadamente, en otros adultos y, sobre todo, en sus hijos niños, adolescentes o jóvenes que, a partir del ejemplo, sin sermones, sin discursos severos, es bastante probable que se interesen en descubrir qué es lo que hay en esos objetos llamados libros que tanto atraen a su padre (p. 219; las cursivas son nuestras).

En nuestro caso, ese adulto que contagiará el placer de leer literatura es el profesor de literatura (un mediador cultural), una persona preparada y apasionada por la literatura. Para contagiar la literatura, debe utilizar unas estrategias didácticas adecuadas para no fracasar en el intento. Aquí sugerimos una estrategia: el modelado estético.

\section{El modelado estético}

La noción de modelado es una contribución de la teoría del 
aprendizaje social cognitivo de Bandura (1984, 1987). Esta teoría sostiene que la mayor parte del aprendizaje humano se produce en un medio social donde como mínimo participan dos personas: el modelo que realiza una conducta determinada y el sujeto que observa dicha conducta. A través de la observación a los otros, el hombre adquiere conocimientos, reglas, habilidades, estrategias, creencias y actitudes (Bandura, 1987). Las fuentes comunes del aprendizaje vicario $^{3}$ (o por observación) consisten en observar o escuchar a modelos en persona, o de manera simbólica en medios electrónicos o impresos. Estas fuentes generan un aprendizaje más veloz que el que se podría adquirir a través de la propia experiencia, porque informan y motivan a los observadores que prefieren aprender las conductas modeladas conducentes al éxito, evitando que la gente experimente consecuencias negativas. Cuando la persona cree que los comportamientos modelados son imitables, observa con mucha atención a los modelos y repasa mentalmente sus procedimientos.

Según Bandura (1984, 1987), el aprendizaje mediante el modelado implica cuatro procesos fundamentales: atención, retención, producción y motivación.
A partir de estos procesos y de la estética general (Gadamer, 1998; Aumont, 2001; Bozal, 1999), proponemos la estrategia del modelado estético, que consiste en la representación espectacular de la literatura por parte del profesor ante los estudiantes previamente motivados. La representación recrea el mundo configurado en los objetos estéticos verbales y muestra las sensaciones y las emociones que padece el actor como efecto de la recepción y la experiencia literaria. Es decir, la representación espectacular consiste en la actualización de la experiencia literaria por medio de la palabra, el discurso, la recitación, la interpretación dramática del texto literario, etc. Por ejemplo, en la lectura expresiva, el profesor modelo "imprime a la voz matices y la entonación necesarios para lograr que los oyentes perciban los sentimientos y el estado de ánimo del escritor cuando plasmó sus ideas en el papel" (Sánchez, 1977, citado en Galera, 1998, p. 115). El profesor tiene que interpretar y representar el texto oralmente como un actor porque la lectura expresiva, como técnica de la comunicación oral, está muy relacionada con la dramatización. "Un buen lector es, en definitiva, a nuestro juicio, una especie de actor que interpreta el pensamiento encerrado en una letra muerta a la que él le da vida. Su entonación, su dicción, su gesticulación, incluso, de locutor se asemeja a una dramatización" (Galera, 1998, p. 114). Así, el profesor, como lector modelo, transmite el gusto de leer e invita a los alumnos a ser lectores.

El profesor de literatura constituye el modelo de la lectura expresiva en cuanto su demostración espectacular da vida a la historia de los textos literarios, cautiva la imaginación de sus alumnos y sirve de modelo imitable. Utilizando su voz, transforma las letras en una cadena de sensaciones auditivas con efecto emocionante y provoca en los estudiantes el deleite y el placer de la imaginación creadora. Así, contagia su pasión de vivir la literatura; impregna la fascinación por la lectura literaria; deja una huella marcada en la experiencia literaria de sus estudiantes. Su actuación modélica supera las teorías y las didácticas de la enseñanza de la literatura.

La experiencia literaria, como imaginación o sentido, ingresa a la mente por medio de la sensibilidad y los sentimientos estéticos del sujeto modelo o profesor de literatura. Las sensaciones estéticas constituyen el placer de los sentidos y son los medios por los cuales accedemos al mundo ficcional.

\footnotetext{
3 En el marco de la teoría de aprendizaje social, según Bandura (1987), el aprendizaje ocurre en acto, mediante la ejecución o experiencia directa, o en modo vicario, por la observación de la conducta de los modelos.
} 
El texto literario es un objeto artístico y es, por su naturaleza, fuente de placer sensorial y cognitivo. Como señala Aumont (2001), “[e]1 arte es fuente de placer, de un placer sensorial afectivo que eventualmente se prolonga en un placer intelectual o en beneficio espiritual" (p. 71). Una obra de arte encarna emociones e influye en la respuesta emocional del receptor; tiene la función natural de producir efectos estéticos. Por ello, la recepción de un texto literario suele provocar miedo, terror, pánico, simpatía, alegría, identificación, entre otras reacciones en el lector.

A través de la representación artística, el profesor de literatura actúa con el propósito de impresionar al estudiante (espectador) como un verdadero poeta, narrador o dramaturgo apasionado que comparte su arte, porque "el arte está hecho para gustar" o agradar a los demás (Gadamer, 1998, p. 86). Así genera un interés estético en los alumnos para contagiar o transmitir el sentimiento estético por la literatura. El contagio del sentimiento o la pasión literaria es un proceso que consiste en la educación de la sensibilidad literaria de los alumnos de educación básica que entran en contacto con la literatura, o de los que, estando en el nivel superior, aún no sienten nada por la literatura y menos tienen competencia literaria.

El desarrollo de la sensibilidad literaria es fundamental para la práctica de la comunicación literaria en la sociedad, dado que "la apreciación estética de las obras de arte se funda en la sensibilidad, en el sentimiento que las mismas proporcionan" a través de su lenguaje particular (Aumont, 2001, p. 71). Entonces, la apreciación de la literatura exige la natural reacción de los sentimientos. Pero esto no significa que el receptor de la literatura se quede en el nivel de placer de los sentidos, sino que, a través de este nivel sensitivo como condición necesaria, puede llegar al nivel cognitivo que constituye la configuración del sentido del texto. Porque "el placer estético surge del libre juego de imaginación y entendimiento" (Bozal, 1999, p. 74).

\section{Procedimientos didácticos}

El procedimiento didáctico del modelado estético se inspira en los procedimientos establecidos por Pozo (1999), quien, siguiendo las ideas de Bandura, propone un procedimiento general del modelado de cinco fases ${ }^{4}$. A partir de esta secuencia general de modelado, proponemos una estrategia específica de cuatro fases para contagiar la literatura: introducción de información relevante, presentación del modelo literario eficaz, producción de la comunicación literaria, y valoración y reforzamiento de las habilidades literarias de los estudiantes. Estas secuencias, con el apoyo de ciertas técnicas, permitirán desarrollar la sensibilidad literaria.

\section{La introducción de informa- ción relevante}

Una de las acepciones del término introducción, según la Real Academia Española (2014), es la "[p] reparación, disposición para llegar al fin propuesto". Este significado define muy bien la primera fase del procedimiento didáctico: la introducción de información relevante. Esta fase consiste, precisamente, en la preparación adecuada de la atención de los estudiantes para la recepción literaria y el consiguiente planteamiento del objetivo de la comunicación literaria en la clase.

La preparación psicológica de los estudiantes por parte del profesor para la lectura de textos literarios, supone realizar dos actividades de prelectura: la motivación y la contextualización, como

\footnotetext{
Pozo (1999, p. 247) propone cinco secuencias básicas de modelado: (1) la información verbal sobre las habilidades entrenadas y sus objetivos, atrayendo la atención del aprendiz sobre los aspectos más relevantes; (2) presentación de un modelo eficaz, destacando al mismo tiempo esos aspectos fundamentales; (3) práctica de la habilidad entrenada por parte del aprendiz en condiciones simuladas o reales; (4) corrección y, en su caso, reforzamiento de esas habilidades por parte del maestro; y (5) mantenimiento y generalización de esa habilidad a nuevas situaciones.
} 
solía hacer Vladimir Nabokov, caso que se comentará más adelante en este artículo. La motivación, como estímulo para activar la sensibilidad literaria de los estudiantes, crea una actitud positiva y abierta para la interacción con el texto literario; produce expectativas en el imaginario de los alumnos, es decir incita a que ellos realicen predicciones sobre el contenido del texto.

¿Cómo podría modelarse la motivación? No hay más método que el propio cuando uno mismo se ha moldeado como lector apasionado de la literatura. Lo mínimo que puede hacer un profesor modelo para motivar es, primero, enunciar el título del texto con la intención de que los alumnos, intuitiva e imaginativamente, puedan hacer la hipótesis sobre el contenido y el tema del texto y, segundo, compartir la emoción más relevante que ha sentido al leer el texto. El profesor, naturalmente, compartirá sus lecturas de las obras que le agradan y fascinan. Nabokov enseñó a amar las obras que él amaba y prefería. Hablaba sobre las obras que le fascinaban y no sobre las que no le agradaban. Así, la motivación relevante se funda en la verdadera pasión literaria, puesto que tiene la función de invitar al lector a disfrutar el texto literario con el que uno ha gozado.

La contextualización, la otra actividad de la preparación psicológica de los estudiantes, consiste en proveer un adelanto de información implícita o explícita sobre el contexto de producción y recepción del texto. El profesor, según su conocimiento enciclopédico del contexto, puede presentar una serie de informaciones vinculadas con la obra o con el autor. De tal modo, según sea la situación comunicativa, puede presentar a los estudiantes artículos, relatos cortos, titulares de noticias, anécdotas o experiencias relacionadas con el contenido del texto; elementos históricos, sociales, políticos o personales que aparezcan en el texto; una pequeña biografía del autor, la motivación que condujo al autor a crear la obra y las opiniones de los lectores; fotos, dibujos, cuadros y películas relacionados con el tema del texto. Todas estas informaciones deben ser presentadas atractivamente para despertar un interés de entrar pronto en contacto con el texto.

Presentación del modelo literario eficaz

Esta fase consiste en la representación espectacular del texto literario, en la clase o fuera de ella, en la que la palabra escrita cobra vida a través de la voz del lector. En esta representación confluyen el profesor, el texto literario y los alumnos; de tal modo se produce la comunicación literaria. La naturaleza espectacular de la representación infunde la contemplación estética en la que se activan el deleite, el asombro y otros sentimientos afectivos de los estudiantes. La actuación literaria del profesor, a través de la lectura oral, o la recitación, o la declamación, o la narración, etc., debe ser la materialización del disfrute de la recepción del texto literario ante los estudiantes. Esto significa que el maestro debe vibrar con la literatura al leerla, recitarla o comentarla, y debe saber transmitir esa emoción literaria a sus alumnos con el fin de que estos se contagien de la fuerza expresiva de la literatura y admiren el objeto literario por su capacidad de concitar la imaginación y el sentimiento estético. El profesor de literatura, como modelo eficaz, debe marcar una huella profunda en el alma de sus alumnos, "si de verdad se apasiona por la belleza y las misteriosas evocaciones que guardan las palabras envueltas en la admirable maraña de rimas, ritmos y cuantos procedimientos pueden entrañarlas" (Trigo, 1988, p. 295).

La actuación espectacular del profesor también constituye una experiencia estética compartida con los estudiantes. Una experiencia estética como la literaria se justifica por el placer que se siente en el espectáculo literario. La experiencia literaria, una de las formas de la experiencia estética, es un modo de recibir y conocer la ficción a través de la sensibilidad, y 
exige la necesidad de expresar las impresiones que acuden por vía de los sentidos. Expresar las emociones es una facultad natural de comunicar el placer de lo bello ${ }^{5}$. Kant (citado en Aumont, 2001) sostenía que "es posible comunicar el placer de lo bello, porque existe un 'sentido común' de lo bello" (p. 87). Al contemplar el arte literario, todos hacemos una valoración estética en la medida en que experimentamos el deleite estético. Al comunicar las emociones vividas, se juzga un sentimiento que se experimenta en la representación. El ejercicio del juicio estético o de gusto permite transformar una experiencia propia y personal en una experiencia estética compartida con los espectadores.

\section{Producción de la comunica- ción literaria}

Este procedimiento consiste en la lectura de textos literarios por parte de los estudiantes, en la que se produce un acto de creación estética como producto de la interacción del lector con el texto, ya que la obra literaria, según Iser (1987a), cobra vida en la concreción misma. El acto de la creación estética, desde la estética de la recepción, es realizado por el lector 6 . "En el acto de la lectura, el lector procesa el texto y, por tanto, reconstruye el mundo ficcional" (Doležel, 1999, p. 284). El lector, al reconstruir el texto, realiza el acto de la comunicación literaria porque construye el sentido del texto a través de su imaginación, que nace a partir del estímulo de la estructura literaria de la obra. De ese modo, transforma sus propias fantasías (lo inconsciente) en significados sociales, morales e intelectuales (conscientes).

"La comunicación literaria debe ser concebida como un campo intersubjetivo; es preciso entender la relación dialógica entre el texto, sus 'receptores' y los 'receptores' entre sí” (Jauss, 1981, p. 37). La relación dialógica entre el lector (estudiante) y el texto produce un efecto estético en el primero debido a la "reacción emotiva" de éste (Paraíso, 1994, p. 185). El estudiante lector, movido por su reacción emotiva, se conmueve con el texto, se sumerge en la realidad ficcional de la obra, da vida a los personajes, se sorprende con los hechos desconocidos por él, se identifica con la historia creada. Hace una "lectura estética" (Paraíso, 1994, p. 186) en cuanto lee de manera placentera dejándose llevar por la belleza de la obra. Hacer una lectura estética consiste en adoptar una actitud emotiva, no racional, que pone en juego lo sensorial, lo afectivo, lo cualitativo: los sentidos, los sentimientos, las emociones y las intuiciones. Es una lectura intensa, y despreocupada de la extracción de datos del texto. Mediante esta lectura, el lector llega a simpatizar con el mundo creado en la obra o logra identificarse con algún protagonista o personaje central de la historia. Sufre una transformación desde el instante en que se sumerge en el mundo ficcional y emprende un viaje literario guiado por la fuerza del gusto.

La lectura literaria "produce una transformación en el lector" (Sánchez, 2003, p. 297). En el proceso de la transformación, las fantasías personales del estudiante lector originan la imaginación creativa porque la intención del texto literario, como explica Iser (1987a), es, precisamente, activar la imaginación de sus lectores. Entonces, "cada lector enriquece la ficción con su fantasía central, con sus propias asociaciones y las experiencias que se relacionen con ella" (Paris, 2004, p. 33). Esto significa que el estudiante lector reconstruye el texto en función del movimiento de su propia subjetividad o la transformación

\footnotetext{
Lo bello es una valoración estética de una obra que provoca la imaginación y proporciona placer; es una cualidad subjetiva que excita las emociones y conduce al deleite espiritual. Lo bello es lo que a uno le gusta según sus propios criterios subjetivos.

6 Iser (1987a, p. 44) explica que la obra literaria tiene dos polos: uno artístico y otro estético. El polo artístico describe el texto creado por el autor; el polo estético, la concreción realizada por el lector.
} 
de sus propias fantasías. De tal modo, la lectura literaria, como acto de comunicación literaria, no da importancia a las acciones que ocurren en las estructuras verbales del texto, sino a lo que ocurre en la imaginación de los propios estudiantes lectores como consecuencia de la interacción con el texto; propicia la vivencia estética del estudiante en cuanto lo transporta a un mundo de pensamientos, sentimientos $\mathrm{y}$ modos de vida que activan sus representaciones mentales. Así, en el proceso de la lectura literaria, las representaciones o "la configuración del sentido producido por el lector se convierte en una experiencia" (Iser, 1987a, p. 225).

Por otro lado, la producción de la comunicación literaria, como tercer procedimiento didáctico, conlleva, naturalmente, a la comunicación de la experiencia literaria del estudiante lector, que se hace visible en cuanto éste comparte sus "placeres de imaginación" (Addison, 1991) con sus compañeros de clase; porque la comunicación literaria, como ha señalado Jauss (1981) es un campo intersubjetivo. Esto implica que los estudiantes, luego de haber dialogado con el texto y disfrutado la literatura, deben también expresar sus emociones y sus gustos vividos de manera libre y genuina ante sus compañeros y otros. La comunicación de la experiencia literaria consiste en la manifestación del juicio de gusto o de belleza.
Naturalmente, toda recepción del texto literario produce un efecto estético de agrado o desagrado.

\section{Valoración y reforzamiento de las habilidades literarias}

Considerando que la tarea del profesor de literatura consiste "en ayudar al alumno a que la literatura ingrese en su experiencia" estética (Sánchez, 2003, p. 299), en esta fase didáctica el profesor realiza dos acciones formativas fundamentales: la valoración y el reforzamiento de la práctica del acto de la lectura y de la respuesta estética experimentados por los estudiantes lectores. La valoración no consiste en la evaluación de la comprensión del texto como se suele hacer tradicionalmente; mucho menos se valora la participación del estudiante ni sus intervenciones. Consiste en apreciar el acto de lectura que propicia la configuración del sentido que luego se traduce en experiencia literaria personal. Se valora la experiencia literaria, es decir, las representaciones mentales y los juicios estéticos de los estudiantes lectores. La representación mental de la ficción es la respuesta emocional en la mente del estudiante lector, porque "el cerebro interpreta activamente el mundo [literario], utilizando inferencias descendentes que dependen del contexto" (Kandel, 2013, p. 383). Las sensaciones literarias no existen hasta que el cerebro del lector interpreta el texto literario y organiza una respuesta creativa adecuada que concuerde con las expectativas y con el contexto inmediato del estudiante. De tal modo se valoran, entre otros aspectos, las reacciones emotivas que se hacen evidentes mediante las expresiones faciales y corporales, pues "la expresión facial es el principal sistema para transmitir las emociones" (Kandel, 2013, p. 358), ya que transmiten información relevante que permite inferir los sentimientos del lector.

También se valoran todos los juicios o las respuestas estéticas de los estudiantes, que son reacciones emotivas explícitas a partir de la experiencia personal de cada lector. "Los juicios de belleza y placer son infinitos y todos válidos" (Eco, 1970, p. 60). Por consiguiente, todas las apreciaciones, opiniones, valoraciones y comentarios de los estudiantes sobre las obras leídas deben ser valorados por el profesor; porque no existe una interpretación única de los textos literarios. Por ejemplo, Holland observó, por un lado, que diferentes personas leyeron una misma historia pero dieron diversas respuestas; por otro, que un mismo lector, en distintos momentos de su vida, interpreta diferentes sentidos al leer y releer una misma obra (referido en Paris, 2004, p. 14). Las respuestas son múltiples porque cada texto literario es un estímulo estético-verbal que produce diferentes reacciones o experiencias a cada estudiante lector. 
La otra actividad formativa es el reforzamiento de la experiencia literaria de los estudiantes lectores. El profesor de literatura, al reforzar dicha experiencia, por un lado anima y alienta a los estudiantes lectores a seguir disfrutando con los placeres de la imaginación, invita a continuar con la lectura o establece un diálogo espontáneo para compartir las respuestas estéticas o las reacciones emotivas; en suma, encauza positivamente todas las iniciativas literarias que se desprendan del mismo acto de la lectura. Por otro lado, ayuda a los estudiantes con menos sensibilidad literaria a descubrir las satisfacciones de la literatura. Ayudar "llega a ser una cuestión de mejorar la capacidad del individuo para evocar el significado a partir del texto, llevándolo a reflexionar de manera autocrítica acerca de este proceso" (Rosenblatt, 2002, p. 52). Entonces, la tarea del profesor de literatura consiste en propiciar interacciones directas entre los lectores y los textos literarios y contagiar el entusiasmo por la lectura de las obras literarias para que los textos puedan transformarse en experiencias subjetivas de los estudiantes. La acción mediadora del profesor es crucial en el proceso de la educación literaria, pues la "adquisición del gusto por la lectura y el entrenamiento necesario para enfrentarse a textos cada vez más complejos dependen en gran parte de la capacidad del docente para contagiar a sus alumnos el amor por los libros" (Cerrillo y Luján, 2010, p. 9).

Los dos primeros procedimientos didácticos del modelado estético se pueden ilustrar concretamente mediante el análisis de las clases de Vladimir Nabokov ${ }^{7}$ (2010). Para no extendernos mucho en la ejemplificación en este apartado, podemos observar la estructura de la clase de Vladimir Nabokov sobre Madame Bovary (2010, pp. 201-272). Si analizamos la secuencia de esta sesión, advertimos que inicia con la introducción de una información relevante; es decir, la sesión se abre con una motivación, el planteamiento del objetivo y la contextualización. La presentación de la motivación es inmediata y de modo atrayente: "Vamos a disfrutar ahora con otra obra maestra, con otro cuento de hadas. De todos los cuentos incluidos en este curso, la novela de Flaubert Madame Bovary es el más romántico. Estilísticamente, es prosa ejerciendo la función que cumple la poesía" (2010, p. 201; la cursiva es nuestra). La motivación concluye con una breve referencia al contenido de la novela y al efecto que causó su publicación en el gobierno de Napoleón III. Luego enuncia el objetivo central de la clase. El objetivo se plantea desde la mirada de un escritor: "Abordaremos Madame Bovary tal como Flaubert quería que se abordase: como un conjunto de estructuras [...], líneas temáticas, estilo, poesía y personajes". Esta secuencia concluye con la contextualización de la historia principal de la obra y de la escritura de la novela, haciendo énfasis en la explicación de la condición social de los personajes principales.

La segunda secuencia didáctica (presentación del modelo literario eficaz) es una secuencia dominante en la clase de Nabokov. En esta secuencia, Nabokov actúa como un perfecto modelo literario ante sus estudiantes porque se sumerge con pasión irresistible en la misma literatura. Citemos un fragmento de la referida clase para observar su secuencia regular.

En el primer capítulo encontramos nuestro hilo temático inicial: el tema de las capas o de la superposición de capas.

\footnotetext{
Vladimir Nabokov trabajó como profesor de literatura en Wellesley y en la Universidad de Cornell durante veinte años. La transcripción de sus clases, recopiladas póstumamente, da origen a los libros Curso de literatura rusa, Curso de literatura europea y Curso sobre el Quijote. A diferencia de sus colegas de la universidad donde trabajaba, detestaba las teorías literarias. No veía conveniente utilizar las críticas literarias para leer las obras, pues, según él, no era pertinente empezar la lectura con una idea preconcebida sobre una determinada obra. En este sentido, si "uno empieza con una generalización prefabricada, lo que hace es empezar desde el otro extremo, alejándose del libro antes de haber empezado a comprenderlo" (Nabokov, 2010, p. 29). Procuraba que sus estudiantes leyeran directamente los textos literarios como obras de arte.
} 
Corre el otoño de 1828; Charles Bovary tiene 13 años, y en su primer día de escuela, durante la clase, sostiene aún su gorra sobre las rodillas. "Era una de esas gorras de tipo poco definido en las que se pueden descubrir elementos del gorro de piel de oso o de nutria, del chascás de lancero [lancero de casco plano], del sombrero redondo de fieltro, y del gorro de dormir; en fin una de esas prendas lastimosas cuya muda fealdad llega a ser tan profunda como el semblante de un imbécil. Ovoide, abombada con ballenas, empezaba con una especie de triple salchicha circular; luego, más arriba, seguían dos filas de rombos, unos de terciopelo y otros de piel de conejo, separados por una franja roja; a continuación había una especie de bolsa terminada en un polígono de cartón cubierto de un complicadísimo bordado, del que colgaba, en el extremo de un cordón largo y demasiado fino, una borla trenzada con hilo de oro. La gorra era nueva: la visera estaba reluciente".

Aquí, como en los tres ejemplos que vamos a comentar, la imagen se desarrolla estrato por estrato, capa por capa, habitación por habitación, ataúd por ataúd. La gorra, una prenda lastimosa y de mal gusto simboliza toda la vida futura del pobre Charles, igualmente lamentable y desacertada (Nabokov, 2010, p. 206).

Si observamos bien la cita, el momento básico de la clase de Nabokov está constituido por una sucesión intercalada de dos actividades didácticas del profesor: la lectura oral y el comentario literario. Nabokov, como modelo literario, por un lado lee con espectacularidad el texto literario y se detiene en los detalles estéticos que activan su imaginación creadora; lee apasionadamente largos párrafos seleccionados por su valor estético; hace una lectura estética porque se deja seducir por la belleza del texto literario; actualiza oralmente la historia de la novela para cautivar a sus estudiantes. Leía así porque decía que al "leer, debemos fijarnos en los detalles, acariciarlos" (Nabokov, 2010, p. 29). Siguiendo su creencia sobre la recepción literaria, lee la novela en voz alta para ilustrar las ideas que presenta, para desarmar los recursos literarios que se utilizan en la construcción del edificio literario. Su reacción emotiva se evidencia en el acto de la lectura. Se conmueve con la descripción literaria. Goza al desmontar la estructura interna del relato. Por ejemplo, al observar la descripción de la gorra de Charles Bovary, dibuja una gorra con todos los detalles descritos en la obra y deduce el tema de las capas en la novela. Por otro lado, cuando comenta sobre el sentido simbólico de la gorra, Nabokov comunica su experiencia literaria. Su apreciación literaria responde a su reacción intelectual. Se distancia de la reacción emotiva que vivía en el acto de la lectura del texto para valorar la representación de la gorra y luego comunicar su experiencia literaria. A lo largo de la clase, después de cada lectura, comenta con mucha pasión la estructura estética de las representaciones del mundo ficcional, como la de la gorra, la de la torta del matrimonio, la de la casa de Tostes, la de la niñez de Emma, etc. El comentario es una respuesta estética de Nabokov a partir de su interacción personal con la novela; está condicionado por la teoría de la lectura asentada en su esquema mental.

Nabokov tenía una concepción particular sobre el modelo de lector literario. Creía que el lector inteligente, al leer las grandes obras, debe poner en juego la reacción emotiva y la reacción intelectual. La combinación de ambas reacciones en el proceso de la reconstrucción del texto permite lograr el placer de la imaginación y la configuración del sentido del texto. En palabras de Nabokov,

el lector inteligente lee el libro genial no tanto con el corazón, no tanto con 
el cerebro, sino más bien con la espina dorsal. Es ahí donde tiene lugar el estremecimiento revelador, aun cuando al leer debamos mantenernos un poco distantes, un poco despegados. Entonces observamos, con un placer a veces sensual e intelectual, cómo el artista construye su castillo de naipes, y cómo ese castillo se va convirtiendo en un castillo de hermoso acero y cristal (2010, p. 36; la cursiva es nuestra).

Nabokov destaca la lectura emotiva porque cree que la literatura, como cualquier otro arte, es un objeto estético que se siente con la parte sensitiva del alma humana. Su concepción sobre el acto de leer la literatura en la clase coincide con la de Borges, pues ambos creen que la belleza de la literatura cobra vida cuando el lector posee suficiente sensibilidad literaria para emocionarse con los detalles del arte verbal. En este sentido, Nabokov afirma haber enseñado a sus estudiantes a sentir la literatura. "He tratado de enseñaros a leer libros por amor a su forma, a sus visiones, su arte. He tratado de enseñaros a sentir un estremecimiento de satisfacción artística [...] y si alguien piensa que no puede desarrollar su capacidad de placer leyendo a los grandes artistas, entonces es preferible que no los lea" (Nabokov, 2010, p. 552).
El profesor Nabokov es un ejemplo claro del modelo literario eficaz porque era un perfecto seductor. La mayoría de sus alumnos lo recuerdan como un profesor de una sensibilidad irresistible. Era "un actor excepcional, que podía dar la impresión de estar divulgando un secreto, la esencia misma de las cosas: nosotros pensábamos que iba a revelarlo todo", recordaba su alumna Martha Updike (Gómez, 2010, p. 104). Solía recurrir a efectos teatrales para atraer la atención de sus estudiantes. Se empeñaba en contagiar su pasión por la literatura para que sus alumnos pudieran vivir esa sensación de satisfacción al leer las obras literarias. Creía que su misión principal era educar la sensibilidad literaria de sus alumnos para que pudieran sentir el placer de leer.

Los dos últimos procedimientos de nuestra estrategia (producción de la comunicación literaria y la valoración y reforzamiento de las habilidades literarias) no tienen homología con las secuencias didácticas de la clase de Nabokov porque los estudiantes no participan en su clase. El protagonista principal es el profesor Nabokov. Su función se centra en ser un modelo literario eficaz en el proceso de la recepción literaria. Era consciente de que su estrategia didáctica limitaba la participación de los estudiantes en la clase; tampoco daba lugar a la reproducción de la conducta modelada. Mucho menos hacía el reforzamiento de las iniciativas literarias que surgieran en los estudiantes. Por eso, con cierto sentimiento encontrado, decía: "Mi método de enseñanza me impedía un auténtico contacto con los estudiantes. Todo lo más, regurgitaban unos cuantos trozos de mi cerebro en los exámenes [...]" (Updike, 2010, p. 21). Esas limitaciones metodológicas de Nabokov y de muchos profesores pueden ser resueltas, en cierto modo, con la estrategia del modelado estético, porque se sustenta en la pedagogía dialogante; una pedagogía que reconoce la interacción dialógica entre el profesor y el estudiante. De tal modo, los procedimientos utilizados por Nabokov se complementan con los que proponemos.

\section{Conclusión}

Definimos el contagio de la literatura como la transmisión de un sentimiento estético verbal del profesor de literatura hacia los alumnos, a través del acto de la comunicación literaria modélica, para despertar en ellos el entusiasmo literario que conduzca al disfrute de la literatura. Desde la lógica de esta idea, el sentimiento estético literario no se puede enseñar; solamente se puede transmitir o contagiar porque la experiencia literaria no puede reproducirse mediante operaciones puramente cognitivas. La aprehensión del sentimiento estético literario escapa a la lógica de la 
explicación o abstracción, por esta razón no se puede enseñar el disfrute o el goce de la literatura.

A partir del estudio de las clases de literatura y las creencias sobre la educación literaria del destacado escritor Vladimir Nabokov, hemos propuesto la estrategia del modelado estético como herramienta didáctica para promover el contagio de la literatura en el proceso de la formación literaria de los estudiantes, tanto de la educación básica como de la superior. El análisis de las clases y de las ideas pedagógicas del referido escritor ha permitido descubrir que él tenía un solo principio pedagógico: compartir el placer de leer la literatura con los estudiantes. A la luz de este principio, se dedicó a contagiar su pasión por la literatura a sus alumnos. Cumplió con ese propósito sobradamente porque, como modelo literario eficaz, enseñó a amar las obras literarias como objetos estéticos que representan nuestras vidas.

La estrategia del modelado estético se propone en el marco de la teoría del contagio literario que planteamos en un trabajo anterior. Era necesario desarrollar una metodología para poner en práctica dicha teoría en el proceso de la educación estética verbal. El modelado estético se sustenta en la pedagogía dialogante y en la estética general, pues algunos principios de estas disciplinas orientan, por un lado, los roles que deben cumplir los sujetos de la educación en el proceso de la comunicación pedagógica en el aula $y$, por el otro, la forma de desarrollar la sensibilidad estética de los estudiantes.

El modelado estético es una propuesta didáctica importante para el contagio literario o la educación literaria, pues posee fundamentos y procedimientos ampliamente explicados. La estrategia no tiene una naturaleza normativa porque no establece una secuencia de acciones rígidas para su aplicación; más bien apela a la imaginación y creatividad libre de los maestros a la hora de usarla en el aula de literatura.

\section{Referencias}

Abril, M. (2004). Enseñar lengua y literatura. Málaga: Aljibe.

Addison, J. (1991). Los placeres de la imaginación y otros ensayos. Madrid: Visor.

Altamirano, F. (2012). El contagio de la literatura: otra mirada de la didáctica de la literatura. La Palabra, (21), 21-32.

Argüelles, J.D. (2009). Si quieres... lee. Contra la obligación de leer y otras utopías lectoras. Madrid: Fórcola.

Aumont, J. (2001). La estética hoy. Madrid: Cátedra.

Bandura, A. (1984). Teoría del aprendizaje social. Madrid: Espasa-Calpe.

Bandura, A. (1987). Pensamiento y acción: fundamentos sociales. Barcelona, España: Martínez Roca. 


\section{la palabra}

Barthes, R. (1989). Placer del texto y lección inaugural de la cátedra de lingüistica del Collège de France. México: Siglo XXI.

Borges, J.L. (1980). Siete noches. México D.F.: Meló.

Borges, J.L. (1985). Coloquio. En: R. Llopis. Literatura fantástica (pp. 36-45). Madrid: Siruela.

Bozal, V. (1999). El gusto. Madrid: Visor.

Cassany, D., Luna, M. y Sanz, G. (1998). Enseñar Lengua. Barcelona: Graó.

Cerrillo, P. y Luján, A.L. (2010). Poesía y educación poética. Cuenca: Universidad de Castilla-La Mancha.

Cortázar, J. (2013). Clases de literatura. México D. F.: Alfaguara.

De Zubiría, J. (2011). Los modelos pedagógicos: hacia una pedagogía dialogante. Bogotá: Cooperativa Editorial Magisterio.

Doležel, L. (1999). Heterocósmica. Ficción y mundos posibles. Madrid: Arco/Libros.

Eco, U. (1970). La definición del arte. Barcelona: Martínez Roca.

Gadamer, H. (1998). Estética y hermenéutica. Madrid: Tecnos.

Galera, F. (1998). Lectura expresiva y comunicación oral. Lenguaje y textos, (11-12), 113-128.

Garrido, M.A. (2004). Nueva introducción a la teoría de la literatura. Madrid: Síntesis.

González, L. (2001). Teoría lingüística y enseñanza de la lengua. Madrid: Cátedra.

Iser, W. (1987a). El acto de leer. Teoría del efecto estético. Madrid: Taurus.

Iser, W. (1987b). El proceso de lectura: enfoque fenomenológico. En: J.A. Mayoral (comp.). Estética de la 2 recepción. Madrid: Arco Libro.

Jauss, H.R. (1981). Estética de la recepción y comunicación literaria. Punto de Vista, 12, 34-40.

Jauss, H.R. (1992). Experiencia estática y hermenéutica literaria. Madrid: Taurus.

Kandel, E.R. (2013). La era del inconsciente. Barcelona: Paidós.

Landero, L. (1994). Experiencia pedagógica de un escritor. CLIJ: Cuadernos de Literatura Infantil y Juvenil, 7(63), 26-34.

Lázaro Carreter, F. (1991). Hacia una moderna pedagogía de la literatura. Resumen de ciclo de conferencias impartidas en Fundación Juan March. Recuperado el 20 mayo de 2015, de http://recursos. march.es/culturales/documento s/conferencias/resumenes- bif/557.pdf.

Leibrandt, I. (2008). Las herramientas electrónicas en la didáctica de la literatura. Pamplona: Ediciones Universidad de Navarra.

Lomas, C. (1999). Cómo enseñar a hacer cosas con las palabras (Vol. 2). Barcelona: Paidós. 
Lomas, C. (2002). La educación literaria en la enseñanza obligatoria. Kikirikí. Cooperación educativa, 64, 43-50.

López, M. y Fernández, A. (2005). Enseñar literatura. Buenos Aires: Manantial / Universidad Nacional de general Sarmiento.

Martín, R.A. (2009). Manual de didáctica de lengua y literatura. Madrid: Síntesis.

Mendoza, A. (Coord.). (2003). Didáctica de la lengua y la literatura. Madrid: Prentice Hall.

Nabokov, V. (2010). Curso de literatura europea. Buenos Aires: Del Nuevo Extremo / RBA.

Not, L. (1983). Las pedagogías del conocimiento. México: Fondo de Cultura Económica.

Not, L. (1992). La enseñanza dialogante. Barcelona: Herder.

Paraíso, I. (1994). Psicoanálisis de la experiencia literaria. Madrid: Cátedra.

Paris, D. (2004). Norman Holland y la articulación literatura/psicoanálisis. Madrid: Campo de Ideas.

Pennac, D. (2001). Como una novela. Barcelona: Anagrama.

Pennac, D. (2008). Mal de escuela. Barcelona: Mondadori.

Pozo, I. (1999). Aprendices y maestros. La nueva cultura de aprendizaje. Madrid: Alianza.

Prado, J. (2004). Didáctica de la lengua y la literatura para educar en el siglo XXI. Madrid: La Muralla.

Real Academia Española (2014). Diccionario de la lengua española. Madrid: Espasa.

Rosenblat, L.M. (2002). La literatura como exploración. México, D.F.: Fondo de Cultura Económica.

Rosenblat, L.M. (1996). La teoría transaccional de la lectura y la escritura. En: Textos en contexto 1. Los procesos de lectura y escritura (pp. 13-70). Buenos Aires: Lectura y Vida.

Sánchez, L. (2003). Didáctica de la literatura: relaciones entre el discurso y el sujeto. En: A. Mendoza (comp.). Didáctica de la lengua y la literatura (pp. 290-317). Madrid: Prentice Hall.

Sontag, S. (1984). Contra la interpretación. Barcelona: Seix Barral.

Todorov, T. (2009). La literatura en peligro. Barcelona: Círculo de lectores / galaxia gutenberg.

Trigo, J.M. (1998). Notas sobre la didáctica de la poesía y la recitación. CAUCE, Revista de filología y su didáctica, (11), 289-303.

Updike, J. (2010). Introducción. En: V. Nabokov. Curso de literatura europea (pp. 11-25). Buenos Aires: Del Nuevo Extremo / RBA.

Vigotski, L. (1972). La psicología del arte. Barcelona: Barral Editores.

Vivante, M.D. (2006). Didáctica de la literatura. Buenos Aires: Magisterio del Río de la Plata. 